\title{
Effect of Leachate Circulation on Biogas Production from Market Waste and Rice Straw
}

\author{
Wanninayaka W.M.A.K.W. and Wijethunga S.* \\ Department of Agricultural Engineering, Faculty of Agriculture, University of Ruhuna, Mapalana, \\ Kamburupitiya, Sri Lanka \\ *swije2001@gmail.com
}

\begin{abstract}
The production of biogas from animal waste has been studied and technologies are being used for the management of animal wastes as well as for the generation of renewable energy. The organic fraction of the market garbage as well as agricultural wastes (organic fraction) can properly be affected for the biogas production through proper physiochemical treatments of raw materials.

In this study it was attempted to find out the effect of leachate circulation on biogas production from reactors fed with organic fraction of market waste (MW) and rice straw (RS). The laboratory reactor model $(20 \mathrm{~L})$ was fabricated using plastic cans. The provisions at the bottom and top of the reactor were made to circulate the leachate produced during anaerobic digestion. The leachate circulation was performed using a peristaltic pump. The reactor was fed with $\mathrm{MW} \& \mathrm{RS}(<1 \mathrm{~mm}$ particle size) in the ratio of 1:3. The total raw materials fed to the digester were $3 \mathrm{~kg}$ (dry matter) and total solid level was adjusted to $20 \%$ by adding water. Before starting the experiment inoculums (digested material from a biogas digester running biogas) was added. The experiment was conducted $\sim 3$ months under once a day circulation. Biogas production, temperature and pressure were measured daily. $\mathrm{pH} \&$ Chemical Oxygen Demand of leachate were determined once a week. At the middle of the experiment $\mathrm{CH}_{4}$ was also determined. The $\mathrm{C}$ : $\mathrm{N}$ ratio of the mixture of raw materials fed for the study was $\sim 25: 1$. The consistence biogas production was noted after one week of start of study. Biogas production rate was gradually increased up to $\sim 45$ days and it was decreased at the end of three months period. The total biogas production was $\sim 36 \mathrm{~m}^{3} / \mathrm{kg}$ and its methane content was $\sim 50 \%$. At the beginning of the study $\mathrm{pH}$ was neutral and it was reduced to $\sim 4$ during 6 weeks. Then it has gradually increased due to produced volatile fatty acid by methanogenic bacteria. COD determined in leachate during the study period gradually decreased with the increased biogas production. It was concluded that the biogas production with leachate circulation was very high than without leachate circulation based on the previous trials.
\end{abstract}

Keywords: Biogas, Leachate circulation, Anaerobic digestion 